\title{
Crack Resistance Evaluation on Submarine Pipeline Laying Chun-run $\mathrm{Li}$, Ya-zhang $\mathrm{He},{ }^{*}$ and Hua-qing Yang CNPC Research Institute of Engineering Technology, Tianjin 300451, China CNPC Key Laboratory of Offshore Engineering, Tianjin 300451, China
}

Keywords: Welded Joint, Crack Tip Opening Displacement (CTOD), S-lay, Evaluation.

\begin{abstract}
Submerged arc welding and double torch automatic welding were used in the girth welding of X65 pipeline steel for two-joint-one prefabrication and principal line welding, respectively. The crack tip opening displacement (CTOD) tests of the welded joints were conducted at minus 10 degrees Celsius. The critical CTOD values in pipeline laying process were obtained from the evaluation based on fracture mechanics and compared with the experimental result. The result of comparison showed that the crack resistances of the welded joints in this paper meet the requirement for pipeline laying, so that the pipeline won't crack during S-lay. This method provides reference evidence for the crack resistance evaluation of the welded submarine pipeline laying.
\end{abstract}

\section{Introduction}

Submarine pipeline is an offshore oil and gas production facility with high risk and high investment. It requires high laying speed, high construction quality, safety and environmental protection. Submarine pipeline laying operations are risky and the accidents cause great economic losses. Therefore, it is necessary to conduct a systematic study on the welding procedure of the welded joints and their safety evaluation [1].

S-lay technique is the most technically matured and widely used method currently. The pipe bends naturally into an S-curve under the support of the stinger [2]. Although there is a certain experience in technology and theory of S-lay in deep water, there are some limitations in water depth and the diameter of pipe, etc. especially in the control of crack resistance of the welded joints. The pipeline has a large deformation during the process of laying, which leads to the bearing capacity of the welded joints decrease. The superposition of greater depth of water and wave makes the pipeline easier to broken [3].

Researches show that crack tip opening displacement (CTOD) can evaluate the brittle fracture resistance of the welded joints effectively and accurately, which provide a reliable basis for safety assessment of the structure. In this paper, research was conducted on crack resistance of the welded joints during S-lay. Reasonable control of welding process and the toughness of welded joints hasgreat practical value for submarine pipeline laying.

\section{Welding Experiments}

We used the construction method of SAW and double torch automatic welding (DTAW) to shorten the offshore pipe laying operations. SAW was used for two-joint-one prefabrication in subordinate line and DTAW was used in principal line. The experimental material was X65 pipeline steel and its chemical composition is shown in Table 1. The pipeline is $813 \mathrm{~mm}$ in diameter and $25.4 \mathrm{~mm}$

In thickness. Select the optimal welding process according to the previous welding procedure qualification test. The welding groove and welding layers of SAW are shown in Fig.1. The welding wire was TSW-E40 and the flux was TF-210. The welding groove and welding layers of DTAW are shown in Fig.2. The welding wire was 70S-6. 
Table 1.Chemical composition of X65 steel (mass fraction, \%)

\begin{tabular}{ccccccc}
\hline $\mathrm{C}$ & $\mathrm{Si}$ & $\mathrm{Mn}$ & $\mathrm{P}$ & $\mathrm{S}$ & $\mathrm{Cr}$ & Mo \\
\hline 0.10 & 0.24 & 1.53 & 0.016 & 0.004 & 0.024 & 0.004 \\
\hline \hline $\mathrm{Ni}$ & $\mathrm{Nb}$ & $\mathrm{V}$ & $\mathrm{Ti}$ & $\mathrm{Cu}$ & $\mathrm{Ce}$ & \\
\hline 0.203 & 0.042 & 0.061 & 0.018 & 0.202 & 0.414 & \\
\hline
\end{tabular}

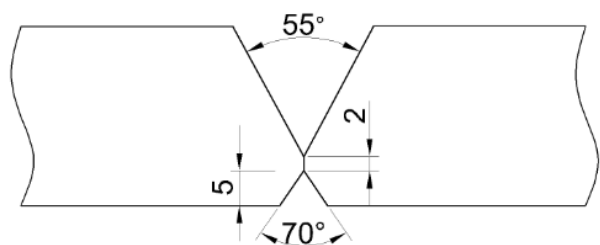

(a)Welding groove

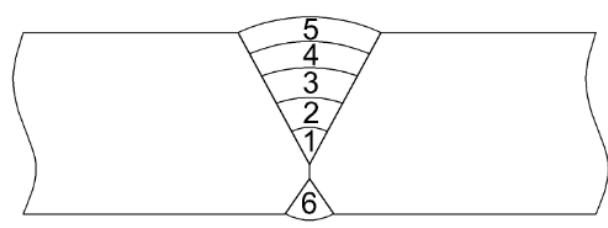

(b) Welding layers

Figure1.Welding groove and welding layers of SAW

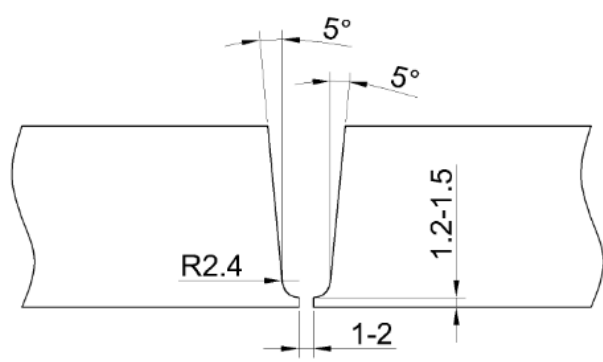

(a)Welding groove

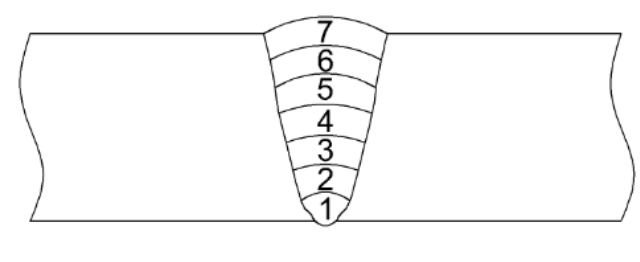

(b) Welding layers

Figure 2. Welding groove and welding layers of DTAW

Well-formed welded joints had been obtained after welding with no surface defects, as shown in Fig.3. X-ray detector showed no defect. Mechanical property tests in accordance with API standard 1104 [4] showed that all the properties of tensile, impact, bending and hardness of both welded joints met the requirement of the pipeline.

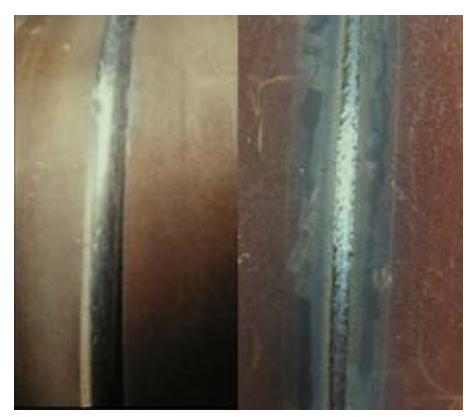

(a) SAW(b) DTAW

Figure3. Weld formation

\section{Calculation of Crack Resistance}

By evaluating based on fracture mechanics, we could determine the influence of different designs 
and manufacturing parameters on the structural safety in the S-lay process in deep water. And then the optimized process could be used in the laying process.

Crack resistance of welded joint was evaluated in accordance with the provisions of British standard BS7910 and the proposed evaluation process. The submarine pipeline design and construction stipulated the technical parameters, standard requirements and process parameters. Use the basic data to analyze and calculate the allowable limit values of fracture toughness for specific sea conditions and water depth. In the analysis and calculation, it was assumed that both the surface crack and the embedding crack were oval or class oval. Fracture mechanics analysis used the Crackwise 4.0 software to conduct the fracture evaluation of level $2 \mathrm{~A}$. The evaluation considered the factors such as pipe dimensions, tensile property, corrosion allowance, elastic modulus, thickness of welding layers, stress intensity magnification factor, film stress and bending stress, etc.

Take the pipeline at the water depth of 100 meters for example. For the DTAW welded joints with outer surface crack or inner surface crack, the CTOD values they need to prevent brittle fracture are shown in Fig.4.

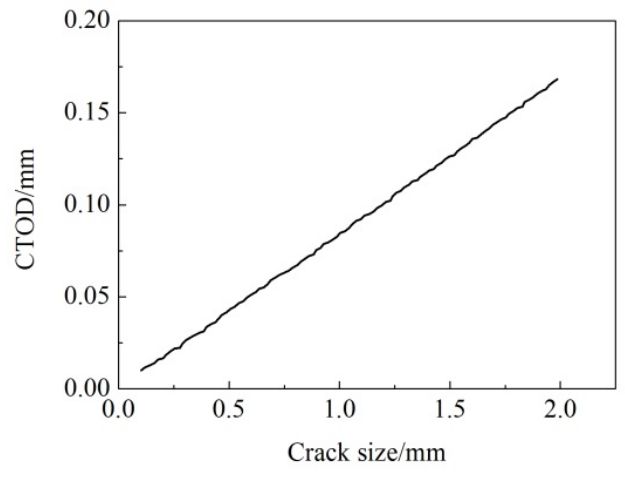

(a) With outer surface crack

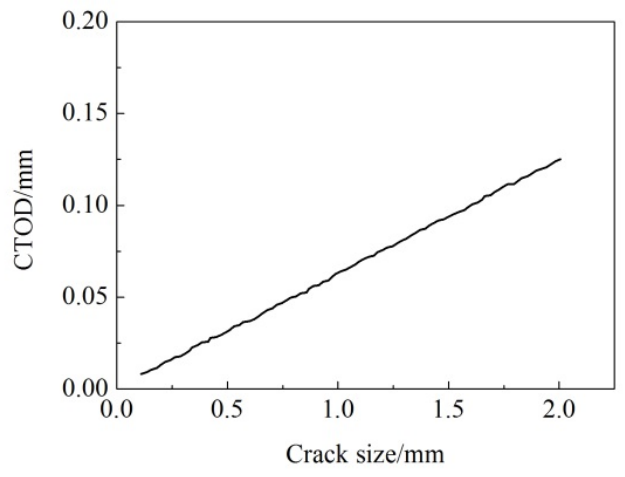

(b) With inner surface crack

Figure 4. The CTOD values needed to prevent brittle fracture

No cracks were found in nondestructive testing during the installation process. The maximum size of the cracks in the thickness direction of the welded joints was selected as $2 \mathrm{~mm}$ according to the accuracy of nondestructive testing. Based on the selection, the requiring CTOD values of the welded joints with critical cracks are shown in table 2.The calculating result shows the following conclusions. SAW welded joints need larger CTOD values than DTAW welded joints. The requiring minimum CTOD values increase with the water depth increasing. The welded joints with outer surface crack need largest CTOD values if other conditions are the same. That is, most likely to crack.

Table 2. The requiring CTOD values of SAW/DTAW welded joints with critical cracks

\begin{tabular}{lcccc}
\hline Type of Crack & Welding Method & CTOD $(60 \mathrm{~m})$ & CTOD $(80 \mathrm{~m})$ & CTOD $(100 \mathrm{~m})$ \\
\hline Embedding Crack & SAW & 0.0372 & 0.0562 & 0.0605 \\
& DTAW & 0.0301 & 0.0459 & 0.0490 \\
Inner Surface Crack & SAW & 0.3069 & 0.3295 & 0.3773 \\
& DTAW & 0.1048 & 0.1154 & 0.1254 \\
Outer Surface Crack & SAW & 0.3255 & 0.3454 & 0.3965 \\
& DTAW & 0.1394 & 0.1536 & 0.1679 \\
\hline
\end{tabular}

\section{Fracture Toughness Test}

Standard three point bend specimens were prepared using the welded joints from the welding experiment. Specimen preparation followed the standard BS EN ISO 15653:2010 [5]. The notches 
were located in the weld center or heat affected zone (HAZ), respectively. Use the high frequency fatigue tester to make prior fatigue crack at room temperature.

The fracture toughness tests were carried out on the electronic universal testing machine. A single loading method was used until the specimen was damaged and then a load - displacement (P-V) curve was obtained. Calculate the CTOD values according to Eq. 1 and Eq. 2. The temperature of the specimens was $-10^{\circ} \mathrm{C}$ during the experiments. Each welding method got a kind of joint and nine experiments were carried out respectively. Six HAZ notched specimens and three weld center notched specimens were tested for each welding method. The analysis and calculates used the minimum value of the results.

$$
\begin{aligned}
& \delta=\left[\frac{F S}{B W^{1.5}} \times f\left(\frac{a_{0}}{W}\right)\right]^{2} \times \frac{1-\mu^{2}}{2 \sigma_{Y S} E}+\frac{0.4\left(W-a_{0}\right) V_{p}}{0.4 W+0.6 a_{0}+z} \\
& f\left(\frac{a_{0}}{W}\right)=\frac{3\left(\frac{a_{0}}{W}\right)^{0.5}\left[1.99-\left(\frac{a_{0}}{W}\right)\left(1-\frac{a_{0}}{W}\right)\left(2.15-\frac{3.93 a_{0}}{W}+\frac{2.7 a_{0}^{2}}{W}\right)\right]}{2\left(1+\frac{2 a_{0}}{W}\right)\left(1-\frac{a_{0}}{W}\right)^{1.5}}
\end{aligned}
$$

Where $\delta$ is the CTOD, $\mathrm{f}\left(\frac{\mathrm{a}_{0}}{\mathrm{~W}}\right)$ is the geometrical shape and dimension of the specimen, $\mathrm{S}$ is the span between outer loading points, $\mathrm{B}$ is the specimen thickness, $\mathrm{W}$ is the specimen width, $\mathrm{F}$ is the maximum force on the $\mathrm{P}-\mathrm{V}$ curve, $\mathrm{Vp}$ is the plastic component of notch opening displacement corresponding to $\mathrm{F}, \mu$ is the Poisson's ratio, $\sigma_{\mathrm{YS}}$ is the $0.2 \%$ proof strength, $\mathrm{E}$ is the Young's modulus elasticity, $\mathrm{a} 0$ is the average original crack length and $\mathrm{z}$ is the distance of the notch opening gauge location above the surface of the specimen.

The fracture toughness test results of the welded joints at $-10^{\circ} \mathrm{C}$ are shown in Table 3 .

Table 3.The fracture toughness test results

\begin{tabular}{ccc}
\hline Welding Method & Weld Center CTOD $/ \mathrm{mm}$ & HAZ CTOD $/ \mathrm{mm}$ \\
\hline SAW & 0.5417 & 0.8165 \\
DTAW & 0.4138 & 0.5358 \\
\hline
\end{tabular}

Comparison of experimental CTOD values and the calculated values are shown in Fig.5. It can be seen that even in the case of getting the minimum value of multiple experiments, the experimental CTOD value is still far greater than the calculated one of the specimen with a critical crack. The welded joints have excellent low-temperature impact toughness, which could meet the construction requirement for submarine pipeline laying.

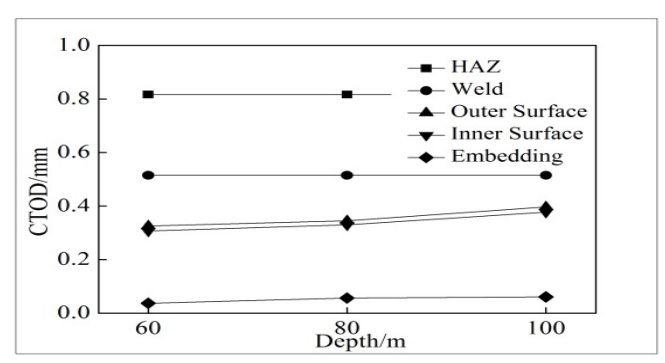

(a)SAW

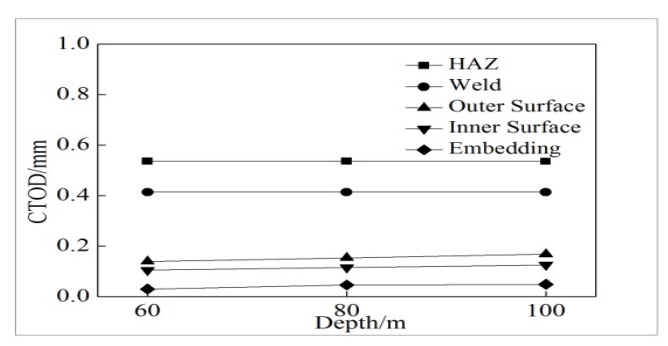

(b)DTAW

Figure5. Comparison of experimental CTOD values and the calculated values 


\section{Conclusions}

The CTOD tests of SAW welded joint and DTAW welded joint for X65 pipeline steel were carried out at minus 10 degrees Celsius. The CTOD values were much greater than the critical CTOD values in pipeline laying process that obtained from the evaluation based on fracture mechanics. The crack resistances of the welded joints in this paper meet the requirement for pipeline laying, so that the pipeline won't crack during S-lay.

\section{References}

[1] FANG Zongtao, LI Chunrun, NIU Huli, et al. Research on Welding Joint CTOD Fracture Toughness by Double Welding Torch Automtaic Welding [J]. Welding Pipe and Tube, 2014, 37(7): $9-12$.

[2] ZHU Liyun. S-lay Installation Analysis for Deepwater Pipeline [D].Harbin: Harbin Engineering University, 2011.

[3] DENG Caiyan. Study on fracture performance and safety assessment of offshore oil and gas pipeline [D]. Tianjin: Tianjin University, 2003.

[4] API STANDARD 1104-2013, Welding of Pipelines and Related Facilities[S].

[5] BS EN ISO 15653-2010, Metallic materials-Method of test for the determination of quasi-static fracture toughness of welds[S]. 